Sistema de información y vigilancia epidemiológica de la encefalitis equina venezolana en la Región de las Américas ${ }^{1}$

1 Basado en el documento de Ruiz A, Zuñiga I y Álvarez E, titulado Bases para la instrumentación de un sistema de información y vigilancia epidemiológica de la encefalitis equina venezolana en la Región de las Américas. Washington, D.C.: Organización Panamericana de la Salud; 1996 (OPS/HCP/96.24).
La notificación de casos de encefalitis equina durante los últimos 15 años ha sido esporádica. Aunque el brote epidémico en Colombia y Venezuela durante 1995 afectó a más de 40000 personas y provocó 46 defunciones, no fue posible obtener datos sobre la morbilidad y mortalidad en los equinos. La dificultad de obtener datos precisos sobre cada epizootia y documentar sus efectos directos e indirectos impide evaluar los daños causados; además, se desconocen las cepas nuevas de los virus, los reservorios silvestres, los tipos de vectores involucrados en cada ciclo enzoótico y la duración de la inmunidad que confiere la vacuna TC-83. En muchos casos, la vacuna se aplica indiscriminadamente, tanto en áreas de riesgo como en áreas sin antecedentes de casos de encefalitis.

Por otra parte, los sistemas de información de los países se limitan a notificar la fecha y el lugar de los casos de enfermedad encefalítica, sin confirmar el diagnóstico ni realizar la investigación del foco, a pesar de que existen pruebas de diagnóstico para identificar las variantes víricas que causan esa enfermedad. Ante la falta de servicios de diagnóstico, la mayoría de los países de América Latina se valen de signos de encefalitis y, en ocasiones, de pruebas histopatológicas para confirmar la presencia de la enfermedad (1).

Esta situación pone de manifiesto que es imprescindible un sistema uniforme de información y vigilancia epidemiológica para las encefalitis equinas, organizado según el modelo adoptado por los programas de prevención y control de la encefalitis equina venezolana (EEV) que ya existen en la mayoría de los países de la Región. El sistema, en el que deben participar los servicios oficiales de salud pública y sanidad animal, permitirá comparar los datos nacionales y regionales y comprender a fondo la dinámica epidemiológica de ese grupo de enfermedades para mejorar las actividades de prevención y control.

A continuación se describen las características generales de la EEV, así como los aspectos epidemiológicos que deben tenerse en cuenta para aumentar la capacidad predictiva de los programas de vigilancia epidemiológica de la EEV y reducir los efectos socioeconómicos adversos de la enfermedad. Posteriormente se describen los procedimientos de diagnóstico de laboratorio que sirven para confirmar la presencia de encefalitis equina en personas con síndromes compatibles con la enferme- 
dad. Por último se explican las características y la estructura de un sistema de información útil para investigar los focos enzoóticos y las zonas de riesgo, pronosticar los brotes y epidemias, detectar de modo precoz las encefalitis y orientar las medidas de prevención y control.

\section{CARACTERÍSTICAS GENERALES}

Las encefalitis equinas constituyen un grupo de enfermedades causadas por arbovirus de la familia Togaviridae. Las de mayor importancia por su distribución y los daños que producen en las Américas son la encefalitis equina del este (EEE), la encefalitis equina del oeste (EEO) y la encefalitis equina venezolana (EEV). La EEV es la forma más grave por la alta morbilidad y letalidad que causa en los solípedos, su importancia para el hombre y la velocidad con que las epizootias y epidemias de la enfermedad pueden trascender las barreras naturales y extenderse a casi todo el continente. Las tres encefalitis equinas mencionadas están citadas en la lista B del Código Zoosanitario Internacional de Epizootias. Los países se comprometen a mantener sistemas de vigilancia e información para notificar los casos de las enfermedades incluidas en la lista B, que agrupa a las enfermedades consideradas más peligrosas desde el punto de vista económico y sanitario (2).

\section{La encefalitis equina venezolana}

La EEV se presenta en la naturaleza en focos enzoóticos y epizoóticos. En los focos enzoóticos o silvestres, el virus causal puede tener una actividad continua o permanecer latente por períodos indefinidos. Su ciclo vital se desarrolla en roedores y aves con la intervención de una gran variedad de mosquitos. Las epizootias ${ }^{2}$ de EEV ocurren en épocas de lluvia en las regiones tropicales y subtropicales de América, después de largos años de silencio aparente. Durante la evolución del brote epizoótico la enfermedad afecta a un gran número de equinos, con gran morbilidad y mortalidad, y grandes cantidades del virus infectan a los seres humanos en un período breve.

El agente causal de la EEV fue aislado por primera vez en 1938 en caballos del Estado Aragua, en Venezuela. La presencia de brotes en el continente americano fue notificada durante el período de 1935 a 1961 y en todos los años siguientes hasta 1973.

\footnotetext{
2 Enfermedades que afectan a una o varias especies animales por una causa general y transitoria.
}

Aunque las epizootias más extensas ocurrieron de 1955 a 1959 en Colombia, Perú, Trinidad y Tabago y Venezuela $(1,2)$, la onda epizoótica más importante ocurrió en 1969: se difundió de Ecuador a Guatemala y más tarde a los otros países de Centroamérica y México, hasta llegar al estado de Texas, en los Estados Unidos, en junio de 1971. Durante esos dos años la epidemia recorrió un territorio de $4000 \mathrm{~km}$, causó decenas de miles de casos humanos y produjo gran morbilidad y mortalidad en los equinos. La gravedad de esa epidemia impulsó a los representantes de los Estados Miembros de la OPS, congregados en la IV Cuarta Reunión Interamericana sobre el Control de la Fiebre Aftosa y otras Zoonosis (RICAZ IV, 1971), a aprobar la creación de un servicio para la vigilancia epidemiológica de la EEV y a designar al Centro Panamericano de Zoonosis (CEPANZO) la tarea de establecer el servicio y coordinar las actividades. La decisión fue ratificada y ampliada en la RICAZ V (1973) y RICAZ VI (1975).

\section{VIGILANCIA EPIDEMIOLÓGICA}

La vigilancia epidemiológica de los virus de las encefalitis equinas comprende el monitoreo de la actividad vírica, las poblaciones de vectores, las infecciones en huéspedes vertebrados, los casos en seres humanos, el clima y otros factores, para poder detectar o predecir cambios en la dinámica de transmisión de los agentes víricos (3). Para proteger la salud humana, es necesario poder definir con precisión las zonas que merecen mayor vigilancia y preestimar la multiplicación del virus de EEV en los equinos. En consecuencia, los programas de vigilancia deben centrar sus actividades en las zonas de mayor concentración de equinos, cercanas a los centros urbanos, o en los focos enzoóticos que ya han sido detectados en el pasado.

El programa de vigilancia debe tener especialmente en cuenta la biología, la ecología y las interacciones entre los huéspedes vertebrados y los mosquitos debido a su influencia en el comportamiento temporal y cíclico de los virus y a que determinadas condiciones ambientales óptimas favorecen el rápido crecimiento de los vectores y la proliferación del virus en los solípedos. El indicador más común de la inminencia de un brote de encefalitis equina es la aparición de casos clínicos en estos animales. La posibilidad de que ocurra una epizootia depende de las características epidemiológicas de cada encefalitis y de la proporción de la población equina inmunizada contra el virus específico. Los mapas basados en el sistema de Holdridge permiten identificar las zonas donde pueden surgir brotes epizoóticos y, recíprocamente, las que permanecen libres de su amenaza. 


\section{Elementos para la vigilancia}

El conocimiento de la ecología local y de la dinámica estacional, el monitoreo de los datos meteorológicos y la vigilancia de los huéspedes vertebrados, vectores y casos en equinos y seres humanos aumentan la capacidad predictiva de los programas para la vigilancia de las encefalitis equinas.

Ecología local. Las peculiaridades locales de la topografía, el clima, la vegetación y los suelos influyen sobre la distribución y población de los vectores, la variedad de los huéspedes vertebrados y el estado inmunitario de los huéspedes, entre otros aspectos. Al mismo tiempo, esas características cambian con el paso del tiempo. Para que los sistemas de vigilancia sean efectivos es necesario establecer series de datos básicos sobre la dinámica espacial y temporal de cada localidad (patch dynamics) $(3,4)$ que abarquen períodos no menores de 5 años. Una vez establecida la base de datos se pueden determinar con certeza la cantidad de vectores y huéspedes susceptibles y las desviaciones esperadas en cada período o estación (mensual, semanal, anual, o época de lluvias, verano, etc.).

Esas modificaciones ecológicas deben tenerse en cuenta cuando se crean condiciones favorables para la aparición de brotes, por ejemplo cuando se programan planes de irrigación, nuevas plantaciones de arroz $u$ otras obras de desarrollo que modifican sustancialmente los ecosistemas. Por lo general, los brotes epidémicos de EEV ocurren en zonas tropicales o subtropicales (matorrales desérticos, montes espinosos, bosques muy secos o secos) donde las lluvias son estacionales y favorecen la formación pasajera de criaderos de mosquitos vectores. En cambio, las endemias ocurren en zonas que favorecen la permanencia de una población de mosquitos vectores (pantanos, costas fluviales o ciénagas). Las zonas con vegetación acuática donde abunda la lechuga de agua (bosques húmedos o muy húmedos) son propicias para la cría de Culex (Melanoconion) de diversas especies que actúan como transmisores entre los vertebrados silvestres (particularmente los roedores pequeños de las especies Sigmodon, Proechimys, Zigodontomys y Hetromys) (5). En esas zonas no se prevén brotes epidémicos a menos que ingresen poblaciones humanas o equinas susceptibles, como en el caso de nuevos asentamientos humanos.

Dinámica estacional. Los factores climatológicos son los primeros predictores de una epizootia porque influyen en el tamaño de las poblaciones de mosquitos vectores. En los países de clima tropical o subtropical, las épocas de mayor riesgo son el ve- rano y la temporada de lluvias en invierno. Los predictores de mediados de la estación permiten estimar la transmisión vírica temprana en el ciclo natural en las poblaciones de vectores y de huéspedes vertebrados. Los predictores estacionales tardíos estiman la propagación del virus en animales centinela, vectores y animales domésticos, en particular los equinos (3).

Factores meteorológicos. La gran variedad de factores ecológicos locales que influyen en la transmisión de los virus de las encefalitis equinas dificulta el uso de los datos meteorológicos para predecir epizootias y epidemias. Los diversos huéspedes vertebrados y especies de vectores responden a los cambios meteorológicos de muchas maneras, según la localización geográfica y otros factores. Aunque la asociación entre las precipitaciones pluviales y la temperatura puede ser de utilidad en ciertas localidades (6), los huracanes y las inundaciones son, sin lugar a dudas, factores predictores de epizootias y epidemias (7). Las corrientes eólicas podrían contribuir a dispersar diversas especies de mosquitos a localidades distantes, pero es difícil determinar sus efectos sobre la trayectoria de la infección vírica de una población equina y humana a otras poblaciones (8).

Vigilancia de los huéspedes vertebrados. Los animales vertebrados silvestres pueden hospedar un gran número de arbovirus, entre ellos los de las encefalitis equinas. Además, pueden ser reservorios de virus aún no detectados. Se conoce una cantidad apreciable de huéspedes vertebrados silvestres y domésticos de los virus de las encefalitis equinas. Pero como las especies varían de una localidad a otra según el hábitat, el clima y demás $(2,9,10,11)$, no se puede usar una sola especie de animal centinela o un solo método de vigilancia para todas las áreas, sobre todo cuando se sospecha la presencia endémica de más de un arbovirus. En el oeste del estado de Texas, en los Estados Unidos, el número de casos de EEO en seres humanos está más relacionado con las tasas de aislamiento del virus en gorriones que con la densidad de los vectores o las condiciones ambientales (3).

Los focos naturales de infección enzoótica de EEV son los roedores silvestres de las selvas húmedas de las regiones tropicales de América; entre ellos, se han identificado las especies Sigmodon, Oryzomys, Peromyscus y Proechimys, los murciélagos y algunos marsupiales (2). Es necesario identificar y caracterizar los focos enzoóticos en cada área porque la vigilancia de los arbovirus abarca una amplia variedad de especies de aves y mamíferos y las po- 
blaciones mixtas de especies pueden estar infectadas con el virus objeto de la vigilancia. La información sobre la población relativa de estas especies animales y su potencial reproductivo, así como sobre las tasas de infección en las especies de huéspedes vertebrados, es útil para diseñar un sistema de vigilancia ajustado a las condiciones y necesidades locales $(3,6,11,12)$.

$\mathrm{Al}$ seleccionar un huésped vertebrado para la vigilancia epidemiológica de las encefalitis equinas deben tenerse en cuenta las características que definen un buen reservorio de arbovirus: su abundancia y susceptibilidad al virus que está en vigilancia, su capacidad para montar una respuesta humoral prolongada con títulos de anticuerpos elevados, la baja morbilidad y mortalidad en la especie y su movilidad local para favorecer la exposición frecuente a los vectores y diseminar el virus. También debe atraer al vector y permitirle la alimentación; ser fácilmente capturable con los métodos convencionales; permitir la obtención de muestras de sangre sin dificultad; permitir la determinación de la edad o la colocación de un marcador con facilidad cuando se necesitan capturas múltiples, y gozar de un ciclo de vida suficientemente prolongado para poder obtener muestras de un mismo ejemplar. Los animales centinela se utilizan para detectar los focos enzoóticos, establecer la presencia del virus y monitorear los cambios temporales y espaciales en una zona determinada. Por ejemplo, el hámster ha demostrado ser un centinela eficaz para la vigilancia de la EEV. El método de vigilancia con animales centinela permite conocer el tipo y lugar exacto de la exposición y conseguir la uniformidad del hábitat, la edad, el origen de los animales y el período de muestreo. Entre las desventajas cabe mencionar que el costo del método lo hace poco viable para la mayoría de los países de América Latina y el Caribe y que ese factor limita el área geográfica de cobertura.

\section{Vigilancia de los casos equinos}

La vigilancia de los casos equinos en las áreas con poblaciones de caballos, asnos o mulas susceptibles permite obtener la información más práctica y sensible para reconocer el riesgo para la salud pública, sobre todo en las localidades donde no hay registros de la actividad del virus en animales silvestres o en mosquitos. La información básica debe reunir datos sobre la población equina, tasas de reproducción, movimientos por razones comerciales o para eventos deportivos, y datos sobre la cobertura de la vacunación (13).

La notificación de síndromes compatibles con la encefalomielitis en equinos debe suscitar la investigación de cada caso que se presenta, te- niendo en cuenta que la vigilancia activa abarca la notificación de casos de equinos sospechosos y la recolección de muestras de sangre para confirmar el diagnóstico en el laboratorio. Asimismo, se aconseja evaluar periódicamente el riesgo de epizootias de EEV u otras encefalitis existentes en la zona por medio de encuestas seroepidemiológicas que determinen el estado inmunitario de la población equina, sin desconocer la posibilidad de que ocurran brotes nuevos a medida que los animales inmunes son reemplazados por animales susceptibles. En consecuencia, se debe considerar estratificar la muestra con un mínimo de dos categorías: animales expuestos a una epizootia previa o vacunados (inmunes) y animales nacidos después de la epizootia (susceptibles).

\section{Vigilancia de los mosquitos}

La vigilancia entomológica ayuda a detectar cambios en la distribución geográfica del vector, medir las fluctuaciones de la población de vectores a lo largo del tiempo, intervenir de modo eficiente y oportuno en su control, e identificar las zonas de alta infestación o los períodos en que aumentan las poblaciones vectoriales. En las zonas donde el vector no está presente, la vigilancia entomológica es crucial para detectar tempranamente la entrada del vector, antes de que sea difícil de eliminar.

La vigilancia de los mosquitos vectores consiste básicamente en dos actividades:

- Identificar los criaderos de larvas y localizarlos en mapas cartográficos para estimar de modo precoz futuras densidades de mosquitos adultos y eliminar los mosquitos en el estado larvario. La creación de un mapa de los lugares óptimos para la cría de larvas de mosquitos constituye el fundamento de cualquier actividad de control de los mosquitos. Los mapas con la ubicación de los principales sitios de cría de mosquitos y de los que poseen altas densidades de adultos deben actualizarse periódicamente. Para ello pueden usarse los sistemas computadorizados de información geográfica.

- Monitorear la variedad de especies, su densidad, estructura de edad y tasas de infección vírica en individuos adultos para obtener datos predictivos que sean incorporados en el sistema de vigilancia de las encefalitis equinas $(3,14)$.

Las estaciones de captura de los mosquitos deben ubicarse lejos de los criaderos de larvas para reducir el número de machos y hembras jóvenes: una proporción elevada de machos en una colecta suele indicar que hay un hábitat larvario en las cer- 
canías. Dada la importancia que tienen los datos sobre la colecta para la programación y evaluación de las actividades de control $(15,16)$, la información debe volcarse en gráficas que ilustren la densidad de los mosquitos en cada estación de captura.

La transmisión de los arbovirus depende de las tasas de supervivencia de las hembras. Como las hembras viejas infectadas viven el tiempo suficiente para transmitir la enfermedad, los programas de vigilancia deben dar por sentada una proporción de hembras más o menos constante en la población total de mosquitos (y una distribución de edad estable) y, por lo tanto, el recuento total de la colecta está directamente relacionado con la transmisión de los arbovirus. Sin embargo, la afirmación no siempre es válida porque en algunos criaderos pueden influir otros factores, tales como la competencia entre las diversas especies de mosquitos por la disponibilidad de nutrientes. La disminución de la tasa de supervivencia larvaria reduce proporcionadamente la población de ejemplares adultos; los adultos que sobreviven tras situaciones muy competitivas son más pequeños y menos robustos (3). Por esa razón, la correlación entre la abundancia de los vectores viejos y la transmisión de arbovirus es más importante que la correlación entre el total de los vectores y la transmisión.

Con referencia a los vectores involucrados en los ciclos epizoóticos, se aconseja programar recolecciones anuales cuando las lluvias estacionales favorecen su proliferación. El aumento de las poblaciones de mosquitos capaces de transmitir el virus de EEV durante las epizootias debe considerarse una situación de alerta. Las especies y géneros más importantes para la transmisión son Aedes scopularis, A. solicitans, A. taeniorrhynchus, Anopheles pseudopunctipennis, Culex nigripalpus, Culex quinquefasciatus, Deinocerites pseudes, Mansonia titillans y Psorophora confinis.

\section{Vigilancia de los casos humanos}

El propósito principal del sistema de vigilancia de las encefalitis equinas es proveer información para prevenir los casos humanos. Cuando se determina un incremento de actividad arbovírica en la población equina o de mosquitos, se debe notificar de inmediato a los servicios locales o nacionales de salud y la sospecha de casos de encefalitis en humanos debe notificarse a los encargados del control de vectores. En las zonas donde se detecte actividad viral de EEV o algún síndrome encefalítico en equinos, deberán vigilarse los casos febriles de personas atendidas en hospitales y centros de salud y obtenerse muestras de sangre de los pacientes para confirmar el diagnóstico en el laboratorio. Si bien la presentación clínica puede variar y no distinguirse de otras formas de encefalitis vírica, todo caso clínico humano que presente fiebre y signos neurológicos (cefalea intensa, somnolencia, náuseas, vómito, etc.) debe definirse como caso probable de EEV y notificarse. Las parálisis de los pares craneales, particularmente el III y IV, son frecuentes y pueden acompañarse de convulsiones y estado de coma (17). La notificación debe hacerse según los requisitos establecidos por el sistema de vigilancia. Además de los datos sobre la edad, el sexo y el lugar de residencia del paciente, deben obtenerse muestras de suero y líquido cefalorraquídeo durante la fase aguda (1 a 7 días después de la aparición de los signos) y la fase de convalecencia (7 a 14 días después de la aparición de los signos).

Los Centros para el Control y la Prevención de las Enfermedades (CDC) de los Estados Unidos de América establecen cinco categorías que determinan la probabilidad de brotes de arbovirus y apuntan a la necesidad de emprender actividades de control (6). Para el caso de la EEV se aplican cuatro categorías (cuadro 1). La similitud clínica de la EEV y el dengue, y la frecuente aparición de las dos infecciones en algunos lugares indican la importancia de determinar con precisión los vectores involucrados en el brote y elegir las medidas de control correspondientes.

\section{DIAGNÓSTICO DE LABORATORIO}

La confirmación del diagnóstico clínico en el laboratorio se realiza mediante el aislamiento y la identificación del virus, o la detección del antígeno o de anticuerpos IgM o IgG específicos. Las muestras para confirmar el diagnóstico pueden ser de sangre completa, suero, líquido cefalorraquídeo o tejidos. Si las muestras no pueden procesarse de inmediato, se deben mantener en hielo seco $\left(\mathrm{a}-70^{\circ} \mathrm{C}\right)$ $y$ enviarse al laboratorio en envases refrigerados.

\section{Detección de anticuerpos}

Las técnicas serológicas como único medio de diagnóstico deben utilizarse con precaución y usualmente requieren una buena historia clínica y pares de muestras (5). Si las técnicas de inhibición de la hemaglutinación $(\mathrm{IH})$ y de seroneutralización $(\mathrm{SN})$ muestran que el título de anticuerpos se ha cuadruplicado entre la toma de las muestras en la fase aguda y en la fase de convalecencia, el resultado se considera confirmatorio. Actualmente, la técnica de electroinmunoensayo enzimático (ELISA) para detectar antígenos y anticuerpos IgG e IgM puede aplicarse tanto a las personas como a los equinos y es 
CUADRO 1. Categorías de riesgo de brotes de encefalitis equina venezolana y respuestas recomendadas

\begin{tabular}{|c|c|c|c|}
\hline Categoría & $\begin{array}{l}\text { Probabilidad } \\
\text { de un brote }\end{array}$ & Definición & Respuesta recomendada \\
\hline 0 & Ninguna & Clima inapropiado, vectores adultos inactivos & Ninguna \\
\hline 1 & Remota & $\begin{array}{l}\text { Época de verano, vectores adultos activos pero no } \\
\text { abundantes, temperatura ambiente que impide } \\
\text { el desarrollo viral en los vectores }\end{array}$ & $\begin{array}{l}\text { Aplicar larvicidas en los sitios identificados por las } \\
\text { encuestas entomológicas, mantener la vigilancia } \\
\text { del virus y los vectores }\end{array}$ \\
\hline 2 & Posible & $\begin{array}{l}\text { Abundancia focal de vectores, temperaturas } \\
\text { adecuadas para la incubación, seroconversión } \\
\text { en huéspedes centinela }\end{array}$ & $\begin{array}{l}\text { Aumentar la aplicación de larvicidas en las áreas } \\
\text { urbanas, iniciar la fumigación selectiva de los } \\
\text { ejemplares adultos, aumentar la vigilancia de } \\
\text { los virus y vectores }\end{array}$ \\
\hline 3 & Probable & $\begin{array}{l}\text { Abundante población de vectores adultos en la } \\
\text { mayoría de las áreas, confirmación de casos } \\
\text { equinos, condiciones óptimas para la incubación } \\
\text { y supervivencia de los vectores }\end{array}$ & $\begin{array}{l}\text { Ejecutar las medidas de control de emergencia: } \\
\text { fumigación de ejemplares adultos en las áreas } \\
\text { de riesgo alto, crear programas para informar a } \\
\text { la comunidad sobre la protección personal } \\
\text { mediante el uso de repelentes y aconsejar que } \\
\text { no concurra a las áreas de alta actividad del } \\
\text { vector, iniciar la vigilancia de casos humanos } \\
\text { en hospitales y centros de salud }\end{array}$ \\
\hline 4 & Brote en proceso & Confirmación de casos humanos & $\begin{array}{l}\text { Continuar con el plan de emergencia: usar los } \\
\text { recursos disponibles para controlar a los } \\
\text { mosquitos adultos en las áreas de riesgo, } \\
\text { seguir informando al público, mantener la } \\
\text { vigilancia del virus/vector y los casos humanos }\end{array}$ \\
\hline
\end{tabular}

una técnica relativamente sencilla y muy útil para analizar un gran número de muestras. Además, es una herramienta para la vigilancia porque permite detectar una infección reciente por la presencia de anticuerpos IgM y antígenos específicos en el suero (18). Los antígenos víricos pueden detectarse durante los 7 días posteriores a la aparición de los signos y los anticuerpos solo pueden detectarse una vez pasada la fase de viremia. Los del tipo IgM aparecen a los 3 días de los primeros síntomas aproximadamente y permanecen detectables entre 70 y 90 días, por lo que su presencia indica una infección reciente. Los anticuerpos del tipo IgG aparecen después de que desaparecen las IgM y pueden detectarse con las pruebas de IH, fijación del complemento (FC) o SN. Como esos anticuerpos permanecen en el organismo durante meses o años, su presencia no indica necesariamente una infección reciente. Debe señalarse también que la presencia de IgG en el feto o el neonato indica la transferencia pasiva de $\operatorname{IgG}$ por la placenta.

La medición de IgM en el líquido cefalorraquídeo es muy útil para el diagnóstico. El hallazgo de anticuerpos IgM en él confirma la respuesta a la infección en el sistema nervioso central y es un indicador para el pronóstico de la encefalitis. La prueba de IH es útil para el tamizaje, aunque varios virus del mismo serogrupo pueden dar resultados positivos a la prueba. Por su parte, la FC es una prueba más específica, pero compleja. Los anticuerpos fijadores del complemento aparecen temprano en la enfermedad y sus títulos suelen ser más bajos que los de los anticuerpos inhibidores de la hemaglutinación. El hallazgo de este tipo de anticuerpos indica una infección reciente y puede utilizarse como prueba presuntiva de infección reciente.

\section{Aislamiento del virus}

El aislamiento del virus de EEV puede realizarse entre cinco y siete días después de la presentación de los síntomas en laboratorios con instalaciones de contención biológica. Los métodos comunes para aislar el arbovirus consisten en inocular a los ratones lactantes con suspensiones de los especímenes por vía intracraneana en líneas celulares como los fibroblastos de embrión de pollo, células VERO y líneas de mosquitos como la C/36 (Aedes albopictus) y la AP-61 (Aedes pseudoscutellaris). Los virus aislados son tipificados por medio de las pruebas serológicas de hemaglutinación de glóbulos rojos de ganso y de FC con preparaciones de anticuerpos homólogos y captura de antígenos por ELISA. La técnica de inmunofluorescencia directa con anticuerpos monoclonales también facilita la identificación del virus. Para las pruebas se deben utilizar anticuerpos específicos contra virus de varios serogrupos, 
virus sospechosos como agentes causales de la enfermedad y virus conocidos que son endémicos en el área de procedencia de la muestra. Las técnicas más recientes, como la reacción en cadena de la polimerasa $(\mathrm{RCP})$ y el secuenciamiento genético, se están usando con más frecuencia para caracterizar las variantes de los aislamientos víricos $(19,20)$.

\section{SISTEMA DE INFORMACIÓN Y VIGILANCIA EPIDEMIOLÓGICA DE LA ENCEFALITIS EQUINA VENEZOLANA}

El objetivo del sistema de información es facilitar y normalizar la recolección, análisis y almacenamiento de los datos sobre la situación de la enfermedad, la detección precoz de las virosis y la orientación de las medidas para su prevención y control.

\section{Definiciones de las encefalitis equinas en los solípedos}

- Caso probable en equino: todo caballo, mula o asno que presente signos clínicos compatibles con las encefalitis equinas (fiebre, depresión profunda, anorexia, somnolencia, tambaleo al caminar) y no haya sido vacunado contra la EEV u otra encefalitis equina.

- Caso confirmado en equino: animal que presenta los signos clínicos descritos más arriba, con detección de antígeno vírico, anticuerpos del tipo IgM en el suero o una duplicación del título de anticuerpos IgG en el suero en un período de 7 días.

- Posible brote de EEV: presencia de dos o más casos equinos en un predio o localidad, con aparición consecutiva de síntomas en un período no mayor de 3 a 5 días.

- Foco: predio con un animal enfermo o más.

- Epizootia: manifestación de la enfermedad en un grupo de animales de una zona geográfica específica (21).

\section{Definiciones de las encefalitis equinas en los seres humanos}

- Caso probable de EEV: todo caso febril procedente de áreas donde se sabe que hubo muertes de équidos o circulación del virus de EEV y que presente durante el curso de la enfermedad:

Personas de 3 años o mayores: cefalea acompañada de convulsiones o alteración del estado de conciencia, desorientación, somnolencia, letargo, coma e hiperacusia, o cualquier trastorno osteomuscular (mialgias, artralgias), gastrointestinal (náuseas, vómito, anorexia, diarrea) o general (escalofríos, fotofobia, postración o malestar).

Niños menores de 3 años: alteración del estado de conciencia o convulsiones.

- Caso confirmado: personas que presentan signos clínicos compatibles con la encefalitis, ya descritos, y cualquier resultado de laboratorio que muestre un aumento del título de anticuerpos IgG en un período de 7 días, el aislamiento del virus en la sangre o el líquido cefalorraquídeo, o la detección serológica de antígenos o de anticuerpos tipo IgM (22).

Como la presentación de la EEV es abrupta, no permite hacer pruebas de laboratorio a todos los casos probables; por lo tanto, una vez que se documenta la circulación del virus en un lugar determinado, no es necesario confirmar todos los casos en el laboratorio.

\section{Aspectos organizativos}

Los países deben establecer los niveles de operación del sistema de información de acuerdo con su propia conveniencia y estructura administrativa. Un sistema de información bien integrado debe contar con unidades de información locales y regionales, unidades de diagnóstico y una unidad central.

Unidades locales de información. Los centros de salud o de agricultura designados en las áreas de riesgo de acuerdo con la estructura de la cobertura geográfica de los sectores funcionan como unidades locales de información. Su responsabilidad abarca las siguientes tareas:

- motivar a la comunidad para que notifique los casos de encefalitis;

- notificar de inmediato y por el medio más rápido a los niveles regional y central de cualquier caso de enfermedad compatible con la encefalitis, en humanos o solípedos;

- atender esas notificaciones y realizar la investigación epidemiológica correspondiente (recolección de muestras y su envío al laboratorio con la información pertinente);

- mantener archivos con el número y ubicación de los predios, la población equina por grupos de edad, los tipos de explotación y la cobertura con la vacuna;

- trazar mapas con la localización de las poblaciones equinas y las concentraciones de animales (hipódromos, clubes, montas del ejército, etc.), las ferias comerciales y de exposición y los distribuidores de productos biológicos; 
- detallar los flujos de movilización de animales indicando su destino (predios, ferias, exposiciones, mataderos);

- informar al centro de salud para que haga el seguimiento de los casos humanos;

- mantener mapas epidemiológicos actualizados con la localización de los focos enzoóticos y los focos de enfermedad equina, según el tipo de encefalitis (del este, del oeste, venezolana) y el subtipo, si se dispone de la información;

- recomendar las medidas de control necesarias de acuerdo con los procedimientos establecidos;

- actualizar los indicadores del comportamiento de la enfermedad (índices y curvas endémicas) utilizando el mes calendario como unidad temporal;

- desarrollar actividades con animales centinela en los focos enzoóticos durante las temporadas anuales de riesgo; y

- vigilar las poblaciones de mosquitos vectores (21).

Unidades regionales de información. Las direcciones departamentales, provinciales o estatales de salud o agricultura que se designen deben asumir las siguientes tareas:

- mantener los archivos de predios y población equina por categorías de edad, tipo de explotación y cobertura regional con la vacuna;

- actualizar la información sobre la situación de las encefalitis;

- poner al día, procesar y analizar la información que envían las unidades locales sobre las poblaciones y coberturas con la vacuna;

- capacitar y asesorar a los funcionarios de las unidades locales y evaluar permanentemente el sistema;

- registrar las notificaciones de los niveles locales y suministrar la información a los otros niveles del sistema, a la unidad regional de salud o a quienes la necesiten;

- caracterizar los ecosistemas de la enfermedad y los diferentes factores y niveles de riesgo;

- dirigir investigaciones ecológicas, epidemiológicas y de impacto económico y participar en ellas; y

- actualizar permanentemente la información sobre los indicadores meteorológicos de la región (21).

Unidad de información de diagnóstico. Los laboratorios de los servicios de salud o de agricultura son los designados para generar la información diagnóstica, de acuerdo con su cobertura geográfica y capacidad técnica. Cada país debe establecer labo- ratorios de diagnóstico de diferentes niveles según el tamaño del territorio que atiende, las vías de acceso y las áreas de riesgo, teniendo además en cuenta la infraestructura y la pericia técnica disponibles. Además del laboratorio central de referencia, los países con diversas áreas endémicas como Brasil, Colombia, México y Venezuela, deben establecer laboratorios regionales para realizar diagnósticos serológicos que apoyen y agilicen las acciones en el campo. Estas unidades deben mantener estandarizadas las pruebas diagnósticas que se utilizan; recibir, registrar y analizar las muestras enviadas por las unidades de campo; informar inmediatamente sobre los resultados de las pruebas a los diferentes niveles del sistema y notificar a la unidad local el nombre del predio y su ubicación en todos los casos en que la unidad de diagnóstico actúe directamente. Asimismo, debe mantener mapas epidemiológicos de los predios afectados, según el diagnóstico, y mantener el registro de muestras recibidas y de resultados, así como de muestras enviadas para un diagnóstico de referencia.

Unidad central de información. La unidad central de información tiene funciones normativas y de orientación técnica y es responsable de archivar, consolidar, analizar y usar la información generada en los otros niveles. Dada la necesidad de integrar los sectores de la salud y la agricultura, es recomendable establecer una comisión nacional intersectorial con atribuciones de coordinación, programación de actividades y evaluación. Sus funciones deben consistir en establecer pautas; supervisar y evaluar la operación del sistema; suministrar informes periódicos, completos y oportunos sobre la situación de las encefalitis y el desarrollo de actividades de los programas de control en los distintos niveles del sistema, los usuarios y los beneficiarios; y capacitar y asesorar a los funcionarios de los diferentes niveles del sistema. Asimismo, debe mantener un banco de datos con información por departamento o estado sobre la distribución de los predios; las concentraciones de animales; las poblaciones de vectores según la especie, categoría de edad, tipo de explotación y cobertura con la vacuna; los laboratorios productores y almacenes que comercializan la vacuna, los registros de personal y su grado de capacitación, y los proyectos de investigación. Por último, es responsable de la coordinación intersectorial para la vigilancia de las encefalitis (21).

\section{Operación del sistema}

Notificación inmediata de encefalitis en equinos. El nivel local (sector agrícola) debe comunicar in- 
mediatamente y por la vía más rápida al nivel regional la presencia inusual o esporádica de casos con signos encefálicos en caballos, mulas o asnos. La información debe incluir la ubicación por cuadrante de los predios afectados, la fecha en que comienza la enfermedad, la especie animal infectada, el número de animales enfermos y muertos, el tipo de muestra y su fecha de envío. También debe confirmar con los servicios de salud la presencia o ausencia de casos febriles humanos en los que se sospecha EEV. Cada notificación debe generar un estudio sobre las características del huésped, el agente y el medio ambiente, así como sobre el origen y la propagación de la enfermedad (si la hubo), y acompañarse de muestras para confirmar el diagnóstico en el laboratorio.

El laboratorio de diagnóstico debe acusar de inmediato el recibo de las muestras a la unidad local remitente y comunicar los resultados de las pruebas a los otros niveles del sistema, utilizando también el medio más rápido que esté disponible. La información debe incluir la fecha en que se recibieron las muestras y se enviaron los resultados; la semana epidemiológica; el nombre y la ubicación del predio afectado; el número y tipo de muestras enviadas; el resultado de laboratorio o la solicitud de muestras nuevas.

Notificación de alerta de brotes (predictores). El nivel local debe vigilar los indicadores predictores de brotes de encefalitis cuando la población equina indemne no vacunada es mayor de $60 \%$, si existe una población abundante de vectores adultos en las áreas de su responsabilidad geográfica y cuando es la época de lluvias con temperaturas de $25^{\circ} \mathrm{C}$ a $30^{\circ} \mathrm{C}$ (favorables para la incubación y reproducción de los vectores). Los encargados de las localidades en las zonas de riesgo señaladas por la unidad central deberán también notificar mensualmente la situación de otros indicadores (temperatura promedio, precipitación pluvial, densidad de crisálidas de mosquitos, taxonomía de los mosquitos adultos capturados y proporción de machos y hembras).

\section{Notificación semanal de la presencia o ausencia de encefalitis}

- La unidad local debe notificar semanalmente (los días viernes) a las unidades central y regional la presencia o ausencia de la enfermedad, incluidos la fecha de aparición de los casos, el receptor, la semana epidemiológica y el nombre del predio y cuadrante donde la enfermedad está presente. Esa notificación también debe abarcar información sobre la investigación de focos.
- La unidad de diagnóstico debe comunicar al nivel central todos los viernes, o de modo inmediato cuando se identifique una encefalitis que se considere "exótica" para una zona determinada, el número y los resultados de los diagnósticos realizados durante la semana con la fecha, receptor, semana epidemiológica, y nombre del predio y cuadrante.

- Basándose en las notificaciones semanales o inmediatas recibidas de las unidades locales, la unidad regional debe comunicar al nivel central todos los martes y por el medio más rápido, la información de la semana anterior, con fecha, unidad regional remitente, semana epidemiológica, nombre de cada predio afectado y su ubicación por cuadrante, e identificación de las unidades locales que no enviaron información (control del sistema).

Todos los niveles del sistema deben comunicar la ausencia de notificaciones o resultados durante la semana epidemiológica correspondiente.

Información sobre operativos de emergencia durante las epidemias. Con el propósito de agilizar el flujo de información y monitorear la evolución de los brotes, es necesario un sistema de información de emergencia que permita tener acceso al informe diario de equinos enfermos y defunciones humanas compatibles con la EEV, el registro diario de vacunación de equinos y el registro de las operaciones de control de la EEV.

\section{Productos de información del sistema}

Boletín epidemiológico semanal. La unidad central debe producir y mandar a los otros niveles del sistema y a los usuarios un boletín epidemiológico semanal basado en la información notificada en el nivel regional, que indique la semana epidemiológica, los predios afectados y la frecuencia acumulada por cuadrante; el municipio y departamento o estado; los diagnósticos confirmados; un mapa con las notificaciones; la comparación con los datos del año anterior (semana y mes acumulado) y las comunicaciones de alerta sobre el comportamiento de la enfermedad. Las unidades regionales deben elaborar boletines usando la misma metodología y enviarlos a los diferentes usuarios del servicio.

Boletín epidemiológico anual. La unidad central debe publicar un boletín anual con información sobre los predios afectados que se identifiquen por departamento, municipio o cuadrante; tipo de ex- 
plotación; población en riesgo; número de enfermos y muertos; tasas de incidencia por especie, y categorías por edad y tipos de diagnóstico. También dispondrá de información sobre el análisis de las epizootias y epidemias, la ocurrencia de la enfermedad en situaciones no esperadas en tiempo y espacio y sus comparaciones, y la cobertura de la vacunación por departamento y municipio. También dará a conocer datos que permitan evaluar la oportunidad de la notificación, la atención del predio, la toma y envío de muestras, y el estado inmunitario de la población equina, evaluado mediante encuestas seroepidemiológicas.

Informes a organismos internacionales. De acuerdo con los compromisos y convenios de cada país, la unidad central del sistema debe enviar un informe semanal sobre la presencia de encefalitis al Centro Panamericano de Fiebre Aftosa (PANAFTOSA) de la OPS, ubicado en Rio de Janeiro, por facsímil o por medio de las Oficinas de País de la OPS. El informe, elaborado durante los primeros días de la semana correspondiente, se basa en las notificaciones de las unidades regionales y debe incluir la ubicación de los cuadrantes afectados, el tamaño de la población equina dentro del área afectada, el número de animales enfermos y muertos y la semana epidemiológica cuyos datos se notifican. También deberá comunicar si hay o no personas enfermas $y$, de haberlas, el número. La unidad central también debe enviar un informe mensual a la Organización Mundial de Sanidad Animal (OIE), elaborado 20 días después de iniciado el mes calendario, utilizando las planillas diseñadas por la OIE a tales efectos. Por último, la unidad debe proveer información sobre los aspectos acordados y con la periodicidad indicada a los países vecinos y a otros países con los que haya celebrado convenios sanitarios.

\section{Flujo de la información}

La operación eficiente del sistema de información depende de la fluidez de las comunicaciones. La información sobre las encefalitis equinas circulará en tres sectores estrechamente relacionados entre sí: el pecuario, el sanitario y el internacional (comprendido por PANAFTOSA, la OIE y los países vecinos o que participan en convenios sanitarios). Dado que la información sobre la actividad vírica en caballos, mulas y asnos proviene del sector pecuario, ese sector debe enviarla al sector de la salud y hacerla circular entre los niveles que corresponda. La notificación inmediata de cualquier actividad vírica en animales integra el flujo de información entre ambos sectores. La unidad local del sector de la salud realizará la investigación correspondiente de los casos humanos febriles y tomará las muestras para confirmar el diagnóstico en el laboratorio. El tercer componente del circuito - el internacionalrecibirá la información de las unidades centrales del sector pecuario y del sector de la salud, según corresponda. En el caso de epizootias y epidemias, conviene establecer una sola unidad central de información que reúna los datos de los dos sectores.

\section{SYNOPSIS}

\section{An information and epidemiological surveillance system for Venezuelan equine encephalitis in the Region of the Americas}

It is difficult to collect precise data on every epizootic and to document the direct and indirect effects of each one. This situation makes it impossible to assess the damage that Venezuelan equine encephalitis (VEE) causes in the Region of the Americas, as well as to identify new encephalitis strains, wild reservoirs, types of vectors in each enzootic cycle, and the period of immunity that the TC-83 vaccine provides. This all shows that, in order to improve prevention and control activities, it is essential to have a standard information and epidemiological surveillance system that involves the official public health and animal health services. This text describes general aspects of VEE and the epidemiological features to consider in order to increase the predictive ability of epidemiological surveillance programs and to reduce the negative socioeconomic effects of the disease. The piece also describes laboratory diagnostic procedures to confirm suspected encephalitis cases. Finally, the text describes the characteristics and structure of an information system that will generate useful data to investigate enzootic foci and areas at risk, make forecasts on outbreaks and epidemics, detect encephalitides quickly, and guide prevention and control measures. 


\section{REFERENCIAS}

1. Ruiz A. Situation of equine encephalitis in the Americas, 1989-1993. Informe presentado en la VIII Inter-American Meeting at the Ministerial Level on Animal Health (RIMSA VIII), celebrada en Washington, D.C. del 27 al 29 de abril de 1993.

2. Acha PN, Szyfres B. Zoonosis y enfermedades transmisibles comunes al hombre y a los animales. 3a ed. Washington, D.C.: Organización Panamericana de la Salud; 1986. (Publicación científica 503).

3. U.S. Centers for Disease Control and Prevention. Guidelines for arbovirus surveillance in the United States. Fort Collins, Colorado: CDC; 1993.

4. White PS, Pickett STA. Natural disturbance and patch dynamic: an introduction. En: Pickett STA, White PS, eds. The ecology of natural disturbance and patch dynamics. Nueva York: Academy Press; 1985.

5. San Martín C. Encefalitis equinas: informe de la asesoría a las autoridades de salud del Perú. Caracas: Organización Panamericana de la Salud; 1981.

6. U.S. Centers for Disease Control and Prevention. Climatic predictors of arbovirus activity. Fort Collins: CDC; 1993. (Arbovirus surveillance summary 2).

7. Sanmartin C. Epidemiological experiences in over-development sub-countries. Amer J Trop Med Hyg 1973;22 (3): 291-295.

8. Sellers RF, Maarouf AR. Trajectory analysis of winds and eastern equine encephalitis in USA, 1980-5. Epidemiol Infect 1990;104(2):329-343.

9. Lord RD, McLean RG. Encephalitis surveillance in Dominican Republic 1988. A report of the Pan American
Health Organization. Washington, D.C.: PAHO; 1988

10. Sudia, WD, Newhouse VF. Epidemic Venezuelan equine encephalitis in North America: a summary of virus-vectorhost relation. Am J Epidemiol 1975;101 (1):1-13.

11. Navarro López R, Flores Hernández AO, Villarroel C, Méndez Ochoa MA, Fraire Chacón M. Estudio epidemiológico para determinar la presencia de virus endémico de encefalitis equina venezolana (EEV) en seis zonas bióticas del Estado de Chiapas, México. Presentado en: Seminario-Taller sobre Vigilancia Epidemiológica de la Encefalitis Equina Venezolana, Chiapas, México, 1996. [Documento mimeografiado].

12. Yuill TM, Homan J E. Venezuelan equine encephalitis in Central America. Propuesta preliminar presentada en la Universidad de Wisconsin, Madison School of Veterinary Medicine, en 1990.

13. Ruíz A. Bases para la instrumentación de un sistema de información y vigilancia epidemiológica de la encefalitis equina venezolana en la Región de las Américas. Seminario-Taller sobre Vigilancia Epidemiológica de la Encefalitis Equina Venezolana. Chiapas, México; 1996.

14. Iversson LB, Silva MS, Travassos da Rosa APA, Barros RS. Circulation of eastern equine encephalitis, western equine encephalitis, Ilheus, Maguari and Tacaiuma viruses in equines of the Brazilian pantanal, South America. Rev Inst Med Trop São Paulo 1993;35 (4);355-359.

15. Monath T P, Sabattini MS, Pauli R Daffner J F, Mitchell CJ, Bowen GS, et al. Arbovirus investigations in Argentina,
1977-1980. IV Serologic surveys and sentinel equine program. Am J Trop Med Hyg 198;34(5):966-975.

16. Scott TW, Weaver SC. Eastern equine encephalomyelitis virus: epidemiology and evolution of mosquito transmission. Adv Virus Res 1989;37:277-328.

17. Roselli D, Piñeros M, Restrepo G, Suazo L J, Vargas F. Manifestaciones neurológicas de la encefalitis equina venezolana. Acta Neurológica Colombiana 1995;11(4):268:271.

18. Ludwig R. Diagnostic approaches for Venezuelan equine encephalitis (VEE). Presentado en el Taller sobre la Vigilancia Epidemiológica de la Encefalitis Equina Venezolana. Chiapas, México; 1996.

19. Rico Heese R. Evolución molecular y epidemiológica del virus de encefalitis equina venezolana. Presentado en Seminario-Taller sobre Vigilancia Epidemiológica de la Encefalitis Equina Venezolana. Chiapas, México; 1996.

20. Rico Heese R, Waver SC, De Siger J, Medina G, Salas RA. Emergence of a new epidemic epizootic Venezuelan equine encephalitis virus in South America. Proc Natl Acad Sci 1995;92:5278-5281.

21. Zuñiga I. Documento base para un sistema de información y vigilancia epidemiológica de las encefalitis equinas para la Región de las Américas. Bogotá: Organización Panamericana de la Salud; 1991.

22. Colombia, Ministerio de Salud. Vigilancia epidemiológica intensificada de la encefalitis equina venezolana. Bogotá: Ministerio de Salud; 1995. [Documento mimeografiado]. 